\title{
Cognitive Evaluation: Is It Time to Require Standardized Assessments?
}

Daniel P. Swiatek

California State University, Dominguez Hills, dswiatek@csudh.edu

Vanessa D. Jewell

Creighton University, vanessajewell@creighton.edu

Follow this and additional works at: https://nsuworks.nova.edu/ijahsp

Part of the Medicine and Health Sciences Commons

\section{Recommended Citation}

Swiatek DP, Jewell VD. Cognitive Evaluation: Is It Time to Require Standardized Assessments?. The Internet Journal of Allied Health Sciences and Practice. 2020 Jan 01;18(1), Article 12.

This Opinion Piece is brought to you for free and open access by the College of Health Care Sciences at NSUWorks. It has been accepted for inclusion in Internet Journal of Allied Health Sciences and Practice by an authorized editor of NSUWorks. For more information, please contact nsuworks@nova.edu. 


\title{
Cognitive Evaluation: Is It Time to Require Standardized Assessments?
}

\begin{abstract}
Mounting evidence from across the medical community supports standardized cognitive assessment and intervention. This manuscript presents a clinical perspective on the benefits of utilization of standardized assessments to inform clinical practice. Today's value-based care initiatives demand standardized testing to support evidence-based practice. Standardized cognitive assessment would wisely be adopted into practice to help practitioners fully identify impairments preventing patients from achieving successful outcomes.
\end{abstract}

\section{Author Bio(s)}

Daniel Swiatek, OTD, OTR/L, is Assistant Professor in the Occupational Therapy Department at California State University, Dominguez Hills.

Vanessa Jewell, PhD, OTR/L, is Assistant Professor in the Occupational Therapy Department at Creighton University in Omaha, NE, and Program Director of its Post-Professional Occupational Therapy Doctorate Program. 


\title{
The Internet Joumnal of Allied Health Sciences and Practice \\ Dedicated to allied health professional practice and education \\ Vol. 18 No. 1 ISSN 1540-580X
}

\section{Cognitive Evaluation: Is it Time to Require Standardized Assessments? An Opinion Piece}

\author{
Daniel P. Swiatek ${ }^{1}$ \\ Vanessa D. Jewell ${ }^{2}$
}

1. California State University, Domingues Hills

2. Creighton University

United States

\begin{abstract}
Mounting evidence from across the medical community supports standardized cognitive assessment and intervention. This manuscript presents a clinical perspective on the benefits of utilization of standardized assessments to inform clinical practice. Today's value-based care initiatives demand standardized testing to support evidence-based practice. Standardized cognitive assessment would wisely be adopted into practice to help practitioners fully identify impairments preventing patients from achieving successful outcomes.
\end{abstract}




\section{Background}

Recent literature indicates use of standardized cognitive assessments are limited in occupational therapy practice, even when clients presented with cognitive limitations.1-5 Occupational therapy practitioners are more likely to rely on interview and observation when assessing cognition. 2,5 This lack of standardized cognitive testing places occupational therapy at odds with initiatives that call for evidence-based practice or EBP. ${ }^{6}$ Cognitive testing may become more urgent if the Centers for Medicare and Medicaid Services (CMS) adopts recent recommendations by the American Occupational Therapy Association (AOTA) to improve assessment of functional cognition in post-acute care settings. ${ }^{7}$ Of greater concern, the lack of standardized cognitive testing may allow client deficits to go unrecognized and untreated. ${ }^{1}$ Practitioners in occupational therapy and other disciplines that assess cognition must consider whether clinicians are overlooking impairments that limit functional performance.

To provide best care, practitioners must utilize research-driven tools to improve the accuracy of clinical decision-making made during treatment. ${ }^{8}$ Standardized assessments are necessary in assuring treatment of the whole person, and specifically capturing mild cognitive impairments which are frequently left untreated. ${ }^{1}$ Mild cognitive impairment is associated with impaired performance of instrumental activities of daily living (IADLs), such as medication management, nutrition management, and keeping medical appointments. ${ }^{1,9}$ Unrecognized and untreated IADL impairments may contribute to poor health outcomes, increased health care costs, and reduced capacity to successfully age in place..$^{9-10}$ In addition, unmet activities of daily living (ADLs) and IADL needs are linked to rates of hospitalization and re-hospitalization. Individuals with unmet functional needs are almost 50 percent more likely to be readmitted to acute. ${ }^{11}$

\section{Early Intervention Necessary and Well-Tolerated}

The prevalence of cognitive impairment is widespread, and the need for early intervention has been recognized. Pandharipande and associates reported that one in four patients hospitalized in the intensive care unit (ICU) demonstrated residual cognitive impairment one year after onset of their illness. ${ }^{12}$ Critical illness should not be a reason to bypass early intervention. Patients in the early stages of a critical illness appear able to tolerate daily physical and cognitive intervention. ${ }^{13}$ Brummel and associates discovered almost all patients in an experimental group of critically ill patients were able to tolerate intervention with no adverse effects as early as 72 hours after admission to the ICU. ${ }^{13}$ In addition, Partridge and associates concluded that a pre-operative assessment of both physical and cognitive functioning may reduce medical complications and hospital length of stay. ${ }^{14}$

\section{Top-Down Versus Bottom-Up Assessment}

Occupational therapists in the United States are not alone in their non-standardized, observational approach to cognitive assessment. Researchers in Canada, Australia, and New Zealand report that occupational therapists prefer to assess cognition in the context of occupational performance, also known as top-down assessment. The majority of therapists, however, choose non-standardized methods for a top-down cognitive assessment. 1,3,4,5 Douglas and colleagues surveyed 247 clinicians to determine how therapists choose a cognitive assessment strategy. ${ }^{3}$ Participants reported choosing a bottom-up assessment, such as the Montreal Cognitive Assessment (MoCA), when therapists wanted to identify specific cognitive deficits. Bottom-up assessments are narrowly focused on a particular cognitive skill and not necessarily a functional task. ${ }^{17}$ Researchers have found that formal assessment is relegated to the most complex cases and typically done so to confirm a clinical assumption rather than to identify unrecognized impairment. ${ }^{4}$ Douglas and associates found that while participants indicated formal tests were useful in identifying deficits, the therapists reported greater preference for a top-down approach as it allows for observation of activities of daily living (ADLs) as well as the effects of cognition. ${ }^{3}$ The researchers noted, however, that the majority of therapists who chose a top-down approach used non-standardized assessment methods versus a standardized top-down assessment. Therapists may be choosing non-standardized tools due to lack of education and comfort level with standardized assessments. Sansonetti and Hoffmann reported that even among therapists who report using standardized cognitive screens, clinicians may not have confidence administering the tests, may not know how to articulate the results, and may be unsure how to apply the findings to real world ADLs and IADLs. ${ }^{5}$

\section{Unrecognized Impairments}

While therapists may prefer utilizing a non-standardized method for evaluation, this practice may allow deficits to go unrecognized. Burns and Neville cautioned that non-standardized methods may only test procedural memory during familiar activities and not higher-level cognitive function. ${ }^{2}$ In other research, Belchior et al noted that occupational therapists appeared challenged in differentiating between declines related to normal aging versus those related to cognitive impairment. ${ }^{1}$ The use of non-standardized tools is problematic because findings may be subjective. ${ }^{1}$ They called for new standards of practice to guide evaluations and proposed occupational therapists take the lead in research and EBP.

\section{Suggestions for Practice}

Research supports early, standardized cognitive assessment, and occupational therapists have been challenged to take the lead. ${ }^{1}$ The following are five suggestions to support EBP and standardized cognitive assessment. 
1. Stay current with American Occupational Therapy Association (AOTA) resources for EBP. Visit the website and click the link, "Evidence-Based Practice \& Research."

(http://www.aota.org/Practice/Researchers.aspx). The website includes guidelines for a variety of populations, an evidence exchange for appraised papers and topics, and EBP resources.

2. Consult a database. Start with Rehabilitation Measures Database (http://www.rehabmeasures.org/default.aspx). ${ }^{15}$ This database features almost 300 screens and assessments. Brief summaries of the instruments are provided, as well as instructions, normative values, and links to the instruments. Many of the assessments are free.

3. Start an assessment club at work. Meet once a month with co-workers and task everyone with researching one new cognitive assessment. Decide as a group which screen is the best fit.

4. Advocate for continuing education and resources. Research continuing education, assessments, and resources that could benefit clients. Talk to management regarding discretionary funds for such resources.

5. Keep the dialogue alive, and practice. Talk to other occupational therapists and find out what standardized cognitive assessments they use. Email former teachers or classmates. Practice administering the screens on co-workers.

Table 1. Standardized Cognitive Assessments

\begin{tabular}{|c|c|c|c|}
\hline Assessment Name & Occupation-Based & Free & Administration Time \\
\hline Executive Function & Yes & Yes & 6-30 minutes \\
\hline Kettle Test & Yes & Yes & 6-30 minutes \\
\hline $\begin{array}{l}\text { Performance Assessment of } \\
\text { Self-Care Skills }\end{array}$ & Yes & No & $60+$ minutes \\
\hline $\begin{array}{l}\text { Routine Task Inventory- } \\
\text { Expanded }\end{array}$ & Yes & Yes & Varies \\
\hline $\begin{array}{l}\text { Brief Cognitive Assessment } \\
\text { Tool }\end{array}$ & No & No & 6-30 minutes \\
\hline Clock Drawing Test & No & Yes & 5 minutes or less \\
\hline Montreal Cognitive Test & No & Yes & 6-30 minutes \\
\hline Saint Louis University Mental & No & Yes & 6-30 minutes \\
\hline
\end{tabular}

Status

Note. All assessments linked on Rehabilitation Measures Database

(http://www.rehabmeasures.org/rehabweb/allmeasures.aspx?PageView=Shared) except for RTI-E, which is located at the Allen Cognitive Network (http://www.allen-cognitive-network.org).

\section{A Professional Responsibility}

One pioneer in the field of standardized cognitive assessment, occupational therapist Claudia Allen, argued 37 years ago that more objective measures were needed for cognitive testing: "Professionals are paid because they know. We realize that we must take steps to refine our knowledge". ${ }^{16}$ Allen's call is more relevant now than ever before as value-based care initiatives demand standardized testing to support EBP. Standardized cognitive assessment would wisely be adopted into practice to help practitioners fully identify impairments preventing patients from achieving successful outcomes.

References

1. Belchior, $P$, Korner-Bitensky, N, Holmes, M, Robert, A. Identification and assessment of functional performance in mild cognitive impairment: A survey of occupational therapy practices. Aust Occup Ther J. 2015; 62: 187-196. http://dx.doi.org/10.1111/1440-1630.12201

2. Burns, SC, Neville, M. Cognitive assessment trends in home health care for adults with mild stroke. Am J of Occup Ther. 2016; 70, 7002290020. http://dx.doi.org/10.5014/ajot.2016.016543

3. Douglas, A, Liu, L, Warren, S, Hopper, T. Cognitive assessments for older adults: Which ones are used by Canadian therapists and why. Can J Occup Ther. 2007; 74(5): 370-381. http://dx.doi.org/10.2182/cjot.07.010

4. Robertson, L, Blaga, L. Occupational therapy assessments used in acute physical care settings. Scand J Occup Ther. 2013; 20: 127-135. http://dx.doi.org/10.3109/11038128.2012.737369 
5. Sansonetti, D, Hoffman, T. Cognitive assessment across the continuum of care: The importance of occupational performance-based assessment for individuals post-stroke and traumatic brain injury. Aust Occup Ther J. 2013; 60: 334-342. http://dx.doi.org/10.1111/1440-1630.12069

6. Leland, NE, Crum, K, Phipps, S, Roberts, P, Gage, B. Health policy perspectives: Advancing the value and quality of occupational therapy in health service delivery. Am J of Occup Ther. 2015; 69: 1-7.

http://dx.doi.org/10.5014/ajot.2015.691001

7. Giles, GM, Edwards, DF, Morrison, MT, Baum, C, Wolf, TJ. Health Policy Perspectives-Screening for functional cognition in postacute care and the Improving Medicare Post-Acute Care Transformation (IMPACT) Act of 2014. Am J of Occup Ther. 2017; 71, 7105090010. https://doi.org/10.5014/ajot.2017.715001

8. Upton, D, Stephens, D, Williams, B, Scurlock-Evans, L. Occupational therapists' attitudes, knowledge, and implementation of evidence-based practice: A systematic review of published research. Br J Occup Ther. 2014; 77(1): 24-38. http://dx.doi.org/10.4276/030802214X13887685335544

9. Ciro, CA, Anderson, MP, Hershey, LA, Prodan, $\mathrm{Cl}$, Holm, MB. Instrumental activities of daily performance and role satisfaction in people with and without mild cognitive impairment: A pilot project. Am J of Occup Ther. 2015; 69, 6903270020. http://dx.doi.org/10.5014/ajot.2015.015198

10. Roberts, PS, Robertson, MR. Health policy perspectives: Occupational therapy's role in preventing acute readmissions. Am J of Occup Ther. 2014; 68: 254-259. http://dx.doi.org/10.5014/ajot.2014.683001

11. Arbaje, A, Wolff, J, Yu, Q, Powe, N, Anderson, G, Boult, C. Postdischarge environmental and socioeconomic factors and the likelihood of early hospital readmission among community dwelling Medicare beneficiaries. Gerontologist. 2008; 48(4): 495-504.

12. Pandharipande, PP, Girard, TD, Jackson, JC, et al. Long-term cognitive impairment after critical illness. N Engl J Med. 2013; 369(14): 1306-1316. http://dx.doi.org/10.1056/NEJMoa1301372

13. Brummel, NE, Girard, TD, Ely, EW, et al. Feasibility and safety of early combined cognitive and physical therapy for critically ill medical and surgical patients: the activity and cognitive therapy in ICU (ACT-ICU) trial. Intensive Care Med. 2014; 40: 370-379. http://dx.doi.org/10.1007/s00134-013-3136-0

14. Partridge, JSL, Harari, D, Martin, FC, Dhesi, JK. The impact of pre-operative comprehensive geriatric assessment on postoperative outcomes in older patients undergoing scheduled surgery: A systematic review. Anaesth. 2014; 69(suppl. 1): 8-16. http://dx.doi.org/10.1111/anae.12494

15. Rehabilitation Measures. Instruments. Rehabilitation Measures Database. http://www.rehabmeasures.org/rehabweb/allmeasures.aspx?PageView=Shared. Accessed April 6, 2019

16. Allen, CK. Independence through activity: The practice of occupational therapy (psychiatry). Am J of Occup Ther. 1982; 36(11): 731-739.

17. Brown, T, Chien, C. Top-down or bottom-up occupational therapy assessment: Which way do we go? Br J of Occup Ther. 2010; 73(3): 95. http://dx.doi.org/10.4276/030802210X12682330090334 